\title{
Ocular surface squamous neoplasia with intraocular tumour extension: a study of 23 patients
}

\author{
Swathi Kaliki ${ }^{1}$ Sai Divya Jajapuram ${ }^{1} \cdot$ Arpita Maniar $^{1} \cdot$ Shikha Taneja $^{1} \cdot$ Dilip K. Mishra $^{2}$ \\ Received: 16 November 2018 / Revised: 4 April 2019 / Accepted: 22 April 2019 / Published online: 10 July 2019 \\ (c) The Author(s), under exclusive licence to The Royal College of Ophthalmologists 2019
}

\begin{abstract}
Purpose To describe the clinical features, histopathology and treatment of ocular surface squamous neoplasia (OSSN) with intraocular tumour extension.

Methods Retrospective study of 23 patients.

Results The mean age at presentation of OSSN with intraocular tumour extension was 48 years. Mass (52\%) and pain with redness (30\%) were the most common presenting complaints. The mean duration of symptoms was 9 months. History of human immunodeficiency virus (HIV) infection was present in eight $(35 \%)$ patients and one (4\%) had xeroderma pigmentosum. History of prior tumour excision was noted in $16(70 \%)$ patients. The mean basal diameter was $17 \mathrm{~mm}$ and the mean tumour thickness was $4 \mathrm{~mm}$. Fifteen (65\%) tumours had a nodulo-ulcerative tumour pattern at the time of detection of intraocular extension of OSSN. Anterior chamber cells and flare was noted in five (24\%) cases and two (9\%) patients had secondary glaucoma. Ultrasound biomicroscopy (UBM) $(n=11)$ revealed blunting of anterior chamber in three $(27 \%)$ cases and uveal thickening in seven $(67 \%)$ cases. Over the course of follow-up, extended enucleation $(n=6 ; 26 \%)$ or orbital exenteration $(n=17 ; 74 \%)$ was required for tumour control. At a mean follow-up period of 18 months, locoregional lymph node metastasis was seen in two (9\%) patients, and one patient died with systemic metastasis. On histopathology, ciliary body was involved in all (100\%) cases.

Conclusion Multiple tumour recurrences with history of prior tumour excision and nodulo-ulcerative tumour pattern are commonly associated with intraocular tumour extension of OSSN. UBM is a useful tool to detect intraocular extension of OSSN.
\end{abstract}

\section{Introduction}

Ocular surface squamous neoplasia (OSSN) includes a spectrum of disease from mild dysplasia to invasive squamous cell carcinoma [1-12]. In a large series of 612 patients with OSSN, the occurrence of dysplasia was 33\%, carcinoma-in-situ was $52 \%$ and invasive squamous cell carcinoma was $11 \%$ [4]. Intraocular tumour extension of OSSN is rare and is reported in $1-15 \%$ cases [5, 13-15].

Swathi Kaliki

kalikiswathi@yahoo.com

1 Operation Eyesight Universal Institute for Eye Cancer, L V Prasad Eye Institute, Hyderabad, India

2 Ophthalmic Pathology Services (DKM), L V Prasad Eye Institute, Hyderabad, India
Intraocular tumour extension of OSSN occurs either due to direct invasion of tumour through the sclera, tumour inoculation via the intraocular surgery incision, or along the tract of the anterior ciliary vessels [16-23]. Based on the published literature, most are individual case reports or small case series [16-23]. Herein, we describe the clinical presentation, histopathology features, treatment and outcome of patients with intraocular extension of conjunctival invasive squamous cell carcinoma.

\section{Methods}

The study was conducted at the Operation Eyesight Universal Institute for Eye Cancer, L V Prasad Eye Institute, Hyderabad, India. Institutional Review Board approval was obtained for the study. A search was conducted in the histopathology database for the diagnosis of "ocular surface squamous neoplasia (OSSN)" diagnosed between the years 
January 2004 and June 2018. All patients with documented evidence of intraocular tumour extension of OSSN were included in the study, and those with no evidence of intraocular tumour extension were excluded.

The following demographic data and history was noted from the medical records: age (years), gender, presenting complaints, duration of symptoms (months), systemic disease, prior history of tumour excision, duration between prior tumour excision and presentation to the oncology clinic, prior history of intraocular surgery, and the duration between prior intraocular surgery and detection with intraocular tumour extension of OSSN. Human Immunodeficiency Virus (HIV) screening was done in all these cases. The clinical details included best-corrected visual acuity (measured by Snellen visual acuity chart), intraocular pressure (IOP) (mm Hg), evidence of secondary glaucoma (IOP $\geq 21 \mathrm{~mm} \mathrm{Hg}$ ), anterior chamber cells or flare, iris neovascularization and co-incidental cataract. The tumour details included tumour laterality, tumour epicentre, tumour extent, tumour size, tumour pattern and associated features (keratin, pigmentation and feeder vessels). Imaging was done in the form of ultrasound B-scan, ultrasound biomicroscopy (UBM) and/or anterior segment optical coherence tomography (AS-OCT) based on clinical suspicion of intraocular extension of OSSN. Computed tomography (CT) or magnetic resonance imaging (MRI) of the orbit was done in cases with tumour extending up to the fornices or beyond.

The treatment details (primary treatment, adjuvant treatment and secondary treatment) were noted. The number of tumour recurrences post-conservative treatment was noted. The time interval between primary treatment and tumour recurrence (months) was noted. Histopathology details included tumour variant, tumour differentiation, extent of intraocular tumour extension and associated intraocular inflammation. The outcome measures included locoregional lymph node metastasis, systemic metastasis and death.

\section{Results}

Of 1102 patients with histopathology-proven OSSN during the study period, 23 (2\%) patients had intraocular extension of OSSN. The demographic details and history are listed in Table 1. The mean age at presentation with intraocular extension of OSSN was 48 years (median, 48 years; range, 5-79 years). There were $16(70 \%)$ males and $7(30 \%)$ females. Mass (52\%) and pain with redness (30\%) were the most common presenting complaints. The mean duration of symptoms was 9 months (median, 4 months; range, 1-60 months). Symptoms of $>6$ months was evident in eight $(35 \%)$ cases. HIV seropositivity was noted in eight
Table 1 Ocular surface squamous neoplasia with intraocular tumour extension: demographics and clinical presentation

\begin{tabular}{lc}
\hline Feature & $n(\%) n=23$ \\
\hline Age at presentation (years) & \\
Mean (median, range) & \\
Gender & $16(48,5-79)$ \\
$\quad$ Male & $7(30)$ \\
$\quad$ Female & \\
Symptoms & $12(52)$ \\
$\quad$ Mass & $3(13)$ \\
$\quad$ Redness & $1(4)$ \\
$\quad$ Pain & $7(30)$ \\
$\quad$ Pain and redness & \\
Duration of symptoms (months) & $9(4,1-60)$ \\
Mean (median, range) & $15(65)$ \\
$\quad \leq 6$ months & $8(35)$ \\
$\quad>6$ months & \\
Systemic disease & $8(35)$ \\
$\quad$ Human Immunodeficiency Virus infection & $1(4)$ \\
Xeroderma pigmentosum & $12(52)$ \\
History of prior intervention for OSSN & $5(22)$ \\
History of prior intraocular surgery & $21(91)$ \\
Tumour laterality & $2(9)$ \\
$\quad$ Unilateral & \\
Bilateral & \\
\hline
\end{tabular}

OSSN ocular surface squamous neoplasia

(35\%) patients and one (4\%) patient had xeroderma pigmentosum (XP). History of prior tumour excision was noted in $16(70 \%)$ patients, 3 patients had received additional mitomycin-C after excisional biopsy and 2 patients had undergone plaque radiotherapy for microscopic tumour residue at the sclera post-excisional biopsy. The mean interval between prior tumour excision and intraocular tumour extension was 7 months (median, 3 months; range, $<1$ month to 35 months). History of prior intraocular surgery of cataract extraction $(n=1)$ or glaucoma filtering surgery $(n=1)$ was noted. Cataract surgery was done 5 years prior to OSSN diagnosis and there was no correlation with OSSN. One patient underwent glaucoma filtering surgery one-month post-OSSN excision for signs of raised IOP and was subsequently detected with intraocular tumour extension through the glaucoma filtering surgery site. History of pterygium excision was noted in two patients and one patient had undergone scleral deroofing due to initial misdiagnosis as necrotising sclerokeratitis.

The clinical features are listed in Table 2. Most (39\%) patients had a diffuse tumour and $24 \%$ patients had additional orbital tumour extension. The mean basal diameter was $17 \mathrm{~mm}$ (median, $17 \mathrm{~mm}$; range, $7-31 \mathrm{~mm}$ ) and the 
Table 2 Ocular surface squamous neoplasia with intraocular tumour extension: clinical features

\begin{tabular}{|c|c|}
\hline Feature & $n(\%) n=23$ \\
\hline \multicolumn{2}{|l|}{ Tumour epicentre } \\
\hline Limbus & $7(30)$ \\
\hline Bulbar conjunctiva & $7(30)$ \\
\hline Diffuse (entire ocular surface involved) & $9(39)$ \\
\hline \multicolumn{2}{|l|}{ Tumour extent } \\
\hline Cornea & $16(70)$ \\
\hline Limbus & $21(91)$ \\
\hline Bulbar conjunctiva & $23(100)$ \\
\hline Forniceal conjunctiva & $12(52)$ \\
\hline Tarsal conjunctiva & $4(17)$ \\
\hline Caruncle & $1(4)$ \\
\hline Orbit & $5(24)$ \\
\hline \multicolumn{2}{|l|}{ Basal tumour diameter (mm) } \\
\hline Mean (median, range) & $17(17,7-31)$ \\
\hline \multicolumn{2}{|l|}{ Tumour thickness (mm) } \\
\hline Mean (median, range) & $4(3,1-15)$ \\
\hline \multicolumn{2}{|l|}{ Tumour pattern } \\
\hline Nodulo-ulcerative & $15(65)$ \\
\hline Nodular & $4(17)$ \\
\hline Papillary & $4(17)$ \\
\hline \multicolumn{2}{|l|}{ Associated tumour features } \\
\hline Keratin & $15(65)$ \\
\hline Feeder vessels & $23(100)$ \\
\hline Tumour pigmentation & $3(13)$ \\
\hline \multicolumn{2}{|l|}{ Associated anterior segment findings } \\
\hline Anterior chamber cells and flare & $5(24)$ \\
\hline Iris neovascularization & $0(0)$ \\
\hline Secondary glaucoma & $2(9)$ \\
\hline
\end{tabular}

AJCC American Joint Committee Classification; there was no view of anterior segment in two patients

mean tumour thickness was $4 \mathrm{~mm}$ (median, $3 \mathrm{~mm}$; range, 1-15 mm). At initial presentation, $15(65 \%)$ had a noduloulcerative pattern (Fig. 1). Anterior chamber cells and flare was noted in five (24\%) cases and two (9\%) patients had secondary glaucoma on presentation. In total, $20 \mathrm{MHz}$ ultrasound B-scan (USG B-scan) was done in 13 cases and it revealed uveal thickening in $2(15 \%)$ cases and anterior chamber tumour extension with blunting of anterior chamber, where the angle of anterior chamber was rounded or was less sharp in $2(15 \%)$ cases. In all, $50 \mathrm{MHz}$ UBM was performed in 11 cases, which revealed uveal thickening in 7 (67\%), scleral involvement in $5(45 \%)$ and blunting of anterior chamber in $3(27 \%)$ cases. AS-OCT was done in four patients and it revealed scleral involvement in one $(25 \%)$ case (Fig. 1) and was inconclusive for intraocular tumour extension due to back shadowing in all cases. CT orbit was done in 10 cases, which showed orbital tumour extension in $5(50 \%)$ cases. MRI orbit was done in one case for suspicion of orbital tumour recurrence post-extended enucleation, which showed tumour recurrence behind the orbital implant.

The treatment and histopathology details are listed in Table 3. Two patients had tumour recurrence after extended enucleation. Both patients underwent orbital exenteration followed by orbital external beam radiotherapy. Overall, 16 (70\%) patients had history of tumour recurrence. Amongst these 16 patients, the mean number of tumour recurrences was 2 (median, 1; range, 1-4). Over the course of followup, extended enucleation $(n=6 ; 26 \%)$ or orbital exenteration $(n=17 ; 74 \%)$ was required for complete tumour control. At a mean follow-up period of 18 months (median, 8 months; range, $<1-109$ months), locoregional lymph node metastasis was seen in two (9\%) patients and one patient died due to systemic metastasis.

On histopathology, invasive squamous cell carcinoma (SCC) was noted in 22 (96\%) cases while invasive mucoepidermoid variant of SCC was noted in one (4\%) patient. Most tumours were well-differentiated (74\%). Ciliary body was involved in all $23(100 \%)$ cases and 11 $(48 \%)$ were associated with intraocular inflammation.

\section{Discussion}

Intraocular tumour extension of OSSN is uncommon with very few reported case series. In our study, intraocular tumour extension of OSSN was noted in only $2 \%$ cases suggesting its rarity. Shields et al. studied five cases of conjunctival squamous cell carcinoma with intraocular tumour extension and concluded that any patient with a history of prior excision of OSSN with associated glaucoma or uveitis or a white mass in the anterior chamber suggests intraocular extension of conjunctival squamous cell carcinoma [23]. In our study, history of prior excision of OSSN and tumour recurrence was noted in $70 \%$ cases before the detection of intraocular tumour extension. Thus, multiple tumour recurrences with history of prior tumour excision should raise an alarm for possibility of intraocular extension of OSSN. Signs of uveitis with anterior chamber cells and flare were noted in $24 \%$ cases and secondary glaucoma was noted in only $9 \%$ cases, suggesting that these signs may not be evident in most cases of intraocular tumour extension of OSSN.

Ancillary tests like AS-OCT and UBM play an important role in determining tumour thickness, tumour shape and tumour extension into the sclera, cornea and intraocular structures [24-28]. AS-OCT is useful to distinguish between intraepithelial versus invasive OSSN. A hyporeflective clear plane of separation is seen beneath the 
Fig. 1 Nodulo-ulcerative ocular surface squamous neoplasia with intraocular tumour extension. a A 56-year-old female presented with right eye noduloulcerative variant of ocular surface squamous neoplasia with scleral thinning, surrounding boggy congested conjunctiva, and overlying keratin.

b Anterior segment optical coherence tomography confirmed the nodulo-ulcerative nature of the lesion with scleral infiltration and scleral thinning. c Ultrasound biomicroscopy showed extension of tumour into the ciliary body.

d Histopathology revealed welldifferentiated squamous cell carcinoma of the conjunctiva with scleral infiltration (Hematoxylin \& Eosin (h\&e stain); $2 \times$ magnification) and e ciliary body infiltration (H\&E stain; $\times 4$ magnification) $\mathbf{f}$ with dense lymphoplasmacytic infiltration interspersed between the tumour islands (h\&e stain; $\times 4$ magnification)

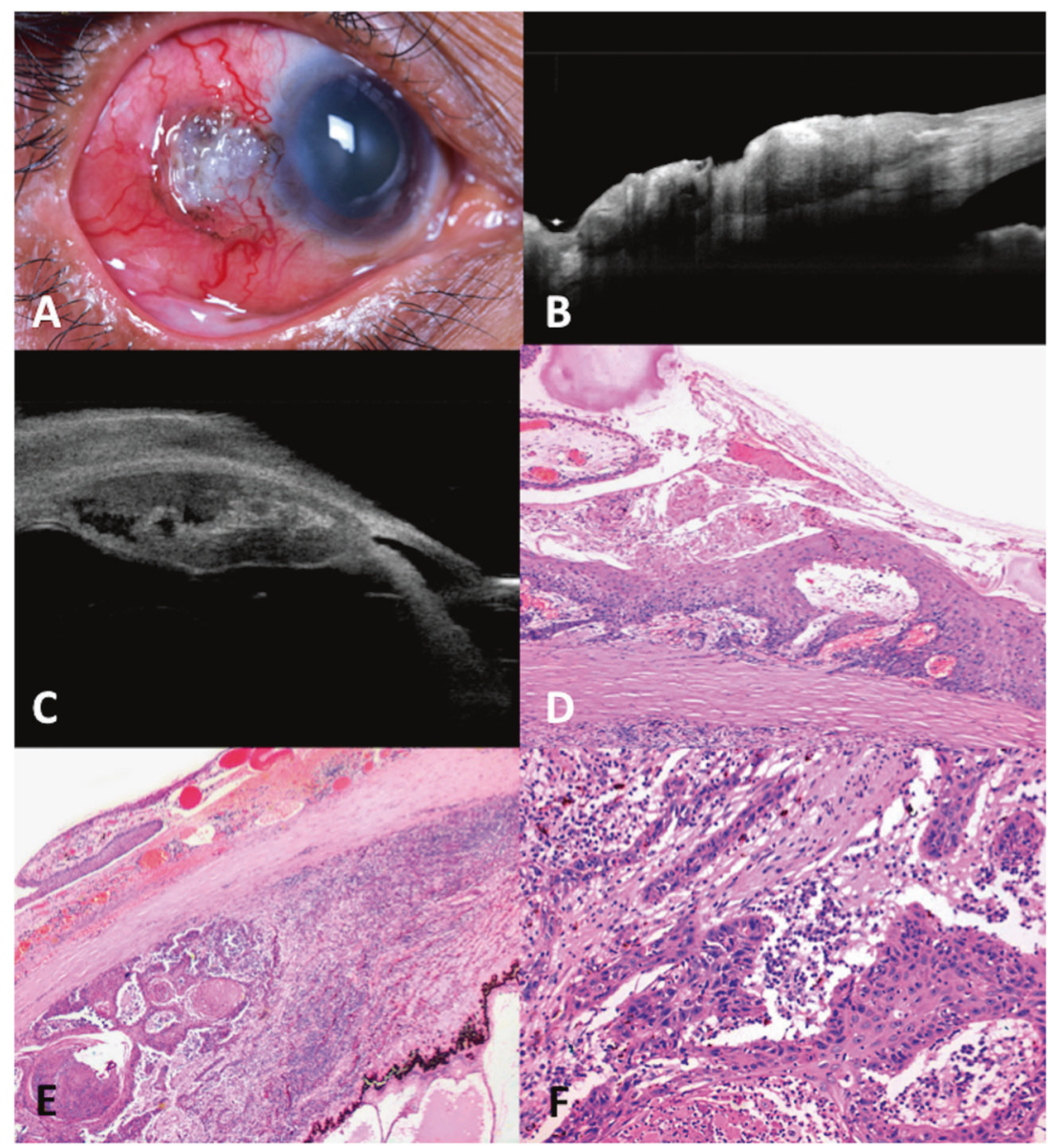

thickened hyperreflective epithelium in 90\% cases of intraepithelial OSSN, while there is no plane of separation in cases of invasive OSSN indicating scleral extension of tumour [27]. Although AS-OCT may be useful to determine the scleral extension of tumour, high frequency ultrasonography $(20 \mathrm{MHz}$ and $50 \mathrm{MHz}$ ) is more informative regarding intraocular tumour extension owing to its ability of greater depth penetration compared to AS-OCT [24-28]. High-frequency ultrasonography with $50 \mathrm{MHz}$ allows better resolution, while $20 \mathrm{MHz}$ ultrasonography allows wider and deeper field of view [24, 25]. High-frequency ultrasonography for OSSN reveals high reflectivity of the tumour surface, with low reflectivity of tumour stroma, and intraocular tumour extension displays varied reflectivity [24]. However, the sensitivity and specificity of these techniques in accurately detecting intraocular tumour extension is undetermined. The signs of intraocular tumour extension using high frequency ultrasonography include blunting of anterior chamber angle and uveal thickening [24]. In our study, AS-OCT $(n=4)$ was inconclusive for intraocular tumour extension due to back shadowing and limited tissue penetration. USG B-scan $(n=13)$ and UBM $(n=11)$ revealed blunting of anterior chamber in two $(15 \%)$ and three (27\%) cases respectively; and uveal thickening in two (15\%) and seven (67\%) cases respectively. This suggests that $50 \mathrm{MHz}$ UBM is more sensitive for detection of intraocular tumour extension of OSSN.

Performing an intraocular surgery with an existing OSSN or a prior history of OSSN may increase the risk of intraocular tumour extension of OSSN [16]. Previous reports suggest intraocular tumour extension of OSSN following cataract extraction and penetrating keratoplasty $[16,17,29]$. The time interval between the intraocular surgery and intraocular extension of OSSN is reported between 0.7 months and 5 months [16, 17, 29]. In our study, there was one patient who developed intraocular extension of OSSN following glaucoma filtering surgery (Fig. 2). In this patient, high IOP was noted 1 month following excisional biopsy of OSSN and glaucoma filtering surgery was done to control the high IOP. Intraocular extension of OSSN was noted within 2 weeks of glaucoma filtering surgery. It is likely that the patient had undetected intraocular tumour extension of OSSN with secondary glaucoma prior to glaucoma filtering surgery, and underwent inadvertent glaucoma filtering surgery, which could have further accentuated the intraocular extension of OSSN. 
Table 3 Ocular surface squamous neoplasia with intraocular tumour extension: treatment, outcome and histopathology features

\begin{tabular}{ll}
\hline Feature & $n(\%) n=23$ \\
\hline Primary treatment & $8(35)$ \\
Extended enucleation & $15(65)$ \\
Orbital exenteration & \\
Adjuvant treatment post-excisional biopsy & $2(9)$ \\
$\quad$ Mitomycin-C & $2(9)$ \\
Plaque radiotherapy & $2(9)$ \\
Secondary treatment for tumour recurrence post-extended enucleation \\
$\quad$ Orbital exenteration & $2(9)$ \\
Outcome & $0(0)$ \\
Locoregional lymph node metastasis & $0(0)$ \\
Systemic metastasis & \\
Death & $22(96)$ \\
Tumour type & $1(4)$ \\
Invasive squamous cell carcinoma & \\
Mucoepidermoid variant & $17(74)$ \\
Tumour differentiation & $5(22)$ \\
Well-differentiated & $1(4)$ \\
Moderately differentiated & \\
Poorly differentiated &
\end{tabular}

Immunosuppression with HIV infection is associated with aggressive OSSN with higher chances of corneal, scleral and orbital tumour extension. In a study of 200 patients with OSSN, comparison between HIV positive and HIV negative patients revealed no significant difference in the incidence of intraocular extension in both groups ( $4 \%$ in HIV positive group vs $5 \%$ in HIV negative group, $p=0.73$ ) [30]. In our study, 35\% patients with intraocular tumour extension were HIV positive. XP is also associated with aggressive form of OSSN and is associated with a recurrence rate of $64 \%$ [31]. However, intraocular extension of OSSN in XP is rare. In our series, one patient with intraocular extension of OSSN had XP. This patient had a history of tumour recurrence post-excisional biopsy and the recurrent tumour invaded the intraocular structures.

The morphological patterns of OSSN include nodular, gelatinous, papilliform, leukoplakic and diffuse forms. Kaliki et al. recently described the nodulo-ulcerative pattern of OSSN, which is characterised by ulceration/necrosis of the conjunctiva and sclera surrounded by indurated and thickened conjunctiva and sclera with associated feeder vessels and keratin [32]. Nodulo-ulcerative OSSN is often misdiagnosed as necrotising scleritis or sclerokeratitis resulting in delayed diagnosis and mismanagement [32-34]. These patients are at increased risk of intraocular tumour extension of OSSN. In a series of six patients with noduloulcerative OSSN, four patients had intraocular tumour extension [32]. In another study by Mahmood et al., all three patients with invasive OSSN presenting as sclerokeratitis had intraocular tumour extension [33]. In our study, $65 \%$ patients with intraocular tumour extension of OSSN had a nodulo-ulcerative pattern at presentation. In our experience, all patients with nodulo-ulcerative OSSN involving the limbus are at risk for intraocular tumour extension. Thus, intraocular tumour extension should be suspected in all patients with nodulo-ulcerative OSSN unless proven otherwise.

Intraocular tumour extension of OSSN is commoner with aggressive variants of OSSN. The incidence of intraocular tumour extension is $7 \%$ with adenoid squamous variant, $29 \%$ with mucoepidermoid variant and 50-67\% with spindle cell variant of OSSN [35-38]. In our study, only one patient had mucoepidermoid variant of OSSN and 74\% had well-differentiated squamous cell carcinoma, suggesting that intraocular tumour extension can occur even in well-differentiated tumours.

The preferred treatment modality for intraocular tumour extension of OSSN is extended enucleation including $4 \mathrm{~mm}$ wide tumour-free conjunctival margins by 'no-touch' technique and adjunctive cryotherapy to the surgical margins of the conjunctiva. Rarely, resection of intraocular tumour and plaque radiotherapy has been used [39, 40]. In cases with extension of tumour till the conjunctival fornices or those with associated orbital tumour extension are best treated by subtotal orbital exenteration. Orbital tumour recurrence post- extended enucleation for intraocular tumour extension of OSSN has been reported [23]. In our study, two patients developed orbital tumour recurrence post-extended enucleation for intraocular tumour extension of OSSN and had to subsequently undergo orbital exenteration and external beam radiotherapy to the orbit. The orbital tumour recurrence could be related to microscopic spillage of tumour cells into the orbit at the time of extended enucleation. Minimal handling of the eyeball and strict 'notouch' technique is recommended at the time of extended enucleation in these cases.

In summary, intraocular tumour extension of OSSN though reported rarely, can occur in cases who have undergone multiple excisions of the tumour and those with 


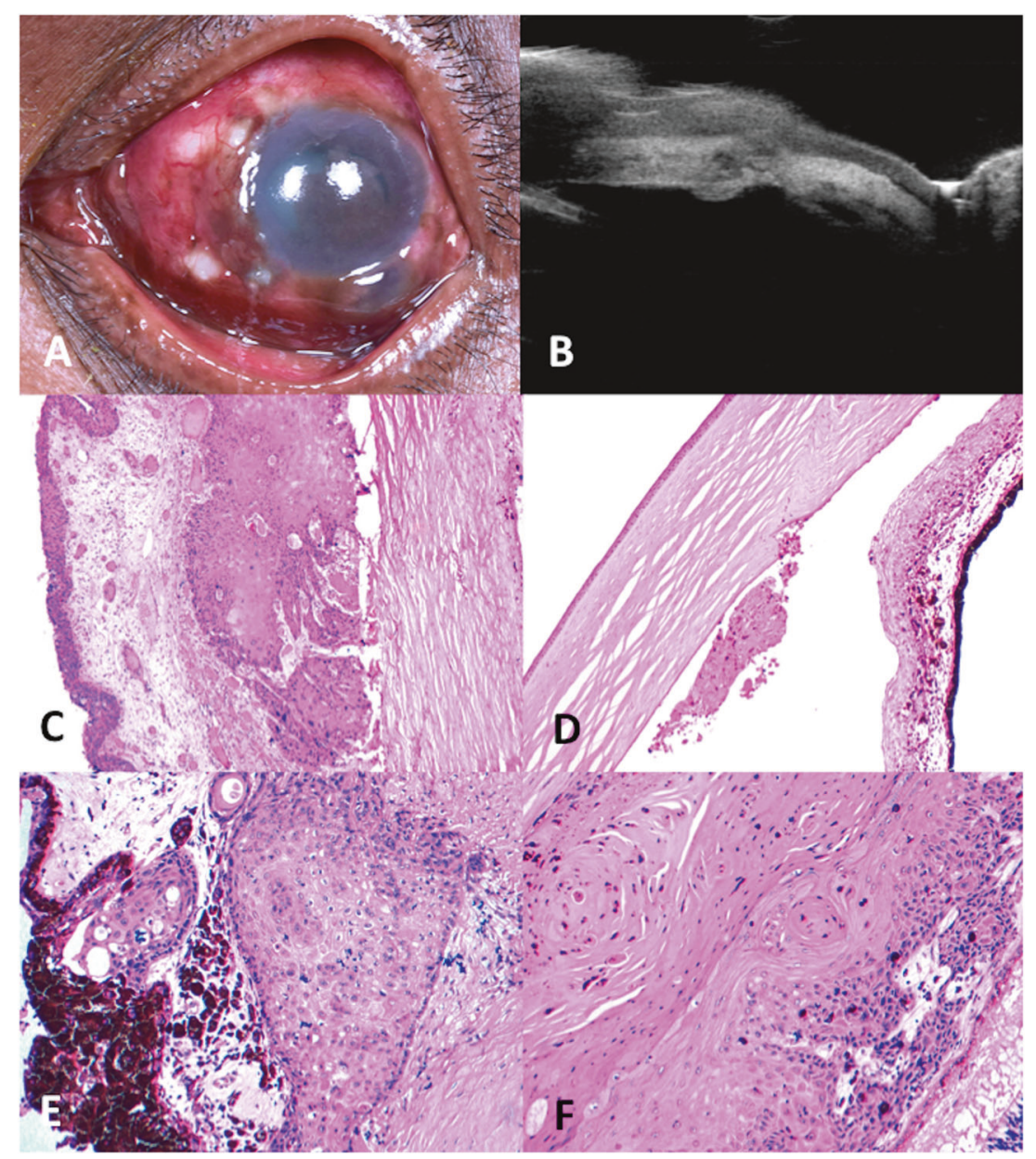

Fig. 2 Intraocular tumour extension of ocular surface squamous neoplasia (OSSN) following glaucoma filtering surgery. a A 42-year-old male had undergone excisional biopsy of OSSN at the nasal limbus with conjunctival autograft 1 month prior to presenting to the oncology clinic. He had also undergone iridencleisis and sclerostomy at 6:00 2 weeks prior to presentation to us. On examination, he had areas of keratin nasally with mild conjunctival bulge, a filtering bleb at 6:00, and a pigmented sheet of tumour cells inferiorly in the anterior chamber. b Ultrasound biomicroscopy showed a tract of tumour

nodulo-ulcerative variant of OSSN. Meticulous screening for intraocular tumour extension with ultrasound biomicroscopy is recommended in all suspicious cases.

\section{Summary}

\section{What was known before}

- Isolated case reports or small case series on intraocular extension of ocular surface squamous neoplasia. extension at the site of glaucoma filtering surgery. c Histopathology showed residual episcleral conjunctival tumour nasally with an overlying normal conjunctival graft (Hematoxylin $\&$ Eosin (h\&e) stain; $\times 4$ magnification). d Necrotic tumour cells in the anterior chamber and iris tumour infiltration (H\&E stain; $\times 4$ magnification). e Welldifferentiated islands of tumour invading the ciliary body (H\&E stain; $\times 10$ magnification) and $\mathbf{f}$ full-thickness choroid (H\&E stain; $\times 40$ magnification)

\section{What this study adds}

- Large series on intraocular extension of ocular surface squamous neoplasia. Clinical features suggestive of intraocular extension of ocular surface squamous neoplasia. Prognosis of patients with this entity.

Acknowledgements Support provided by The Operation Eyesight Universal Institute for Eye Cancer (SK) and Hyderabad Eye Research Foundation (SK), Hyderabad, India. 


\section{Compliance with ethical standards}

Conflict of interest The authors declare that they have no conflict of interest.

Publisher's note: Springer Nature remains neutral with regard to jurisdictional claims in published maps and institutional affiliations.

\section{References}

1. Lee GA, Hirst LW. Ocular surface squamous neoplasia. Surv Ophthalmol. 1995;39:429-50.

2. Grossniklaus HE, Green WR, Luckenbach M, Chan CC. Conjunctival lesions in adults: a clinical and histopathologic review. Cornea. 1987;6:78-116.

3. Basti S, Macsai MS. Ocular surface squamous neoplasia: a review. Cornea. 2003;22:687-704.

4. Kao AA, Galor A, Karp CL, Abdelaziz A, Feuer WJ, Dubovy SR. Clinicopathologic correlation of ocular surface squamous neoplasms at Bascom Palmer Eye Institute: 2001 to 2010. Ophthalmology. 2012;119:1773-6.

5. Yousef YA, Finger PT. Squamous carcinoma and dysplasia of the conjunctiva and cornea: an analysis of 101 cases. Ophthalmology. 2012;119:233-40.

6. Kim BH, Kim MK, Wee WR, Oh JY. Clinical and pathological characteristics of ocular surface squamous neoplasia in an Asian population. Graefes Arch Clin Exp Ophthalmol. 2013;251:2569-73.

7. Tiong T, Borooah S, Msosa J, Dean W, Smith C, Kambewa E, et al. Clinicopathological review of ocular surface squamous neoplasia in Malawi. Br J Ophthalmol. 2013;97:961-4.

8. Erie JC, Campbell RJ, Liesegang TJ. Conjunctival and corneal intraepithelial and invasive neoplasia. Ophthalmology. 1986;93:176-83.

9. Kenawy N, Garrick A, Heimann H, Coupland SE, Damato BE. Conjunctival squamous cell neoplasia: the Liverpool Ocular Oncology Centre experience. Graefes Arch Clin Exp Ophthalmol. 2015;253:143-50.

10. Maudgil A, Patel T, Rundle P, Rennie IG, Mudhar HS. Ocular surface squamous neoplasia: analysis of 78 cases from a UK ocular oncology centre. Br J Ophthalmol. 2013;97:1520-4.

11. Dandala PP, Malladi P, Kavitha. Ocular Surface Squamous Neoplasia (OSSN): a retrospective study. J Clin Diagn Res. 2015;9:NC10-3.

12. Lee GA, Hirst LW. Retrospective study of ocular surface squamous neoplasia. Aust N Z J Ophthalmol. 1997;25:269-76.

13. Tunc M, Char DH, Crawford B, Miller T. Intraepithelial and invasive squamous cell carcinoma of the conjunctiva: analysis of 60 cases. Br J Ophthalmol. 1999;83:98-103.

14. Ogun GO, Ogun OA, Bekibele CO, Akang EE. Intraepithelial and invasive squamous neoplasms of the conjunctiva in Ibadan, Nigeria: a clinicopathological study of 46 cases. Int Ophthalmol. 2009;29:401-9.

15. McKelvie PA, Daniell M, McNab A, Loughnan M, Santamaria JD. Squamous cell carcinoma of the conjunctiva: a series of 26 cases. Br J Ophthalmol. 2002;86:168-73.

16. Murillo JC, Galor A, Wu MC, et al. Intracorneal and intraocular invasion of ocular surface squamous neoplasia after intraocular surgery: Report of two cases and review of the literature. Ocul Oncol Pathol. 2017;3:66-72.

17. Rootman DB, McGowan HD, Yücel YH, Pavlin CJ, Simpson ER. Intraocular extension of conjunctival invasive squamous cell carcinoma after pterygium surgery and cataract extraction. Eye Contact Lens. 2012;38:133-6.
18. Zhang Z, Li B, Shi J, Xu X, Li L, Gao F. Intraocular extension of conjunctival squamous cell carcinoma. Ophthalmologica. 2007;221:200-3.

19. Li WW, Pettit TH, Zakka KA. Intraocular invasion by papillary squamous cell carcinoma of the conjunctiva. Am J Ophthalmol. 1980;90:697-701.

20. Iliff WJ, Marback R, Green WR. Invasive squamous cell carcinoma of the conjunctiva. Arch Ophthalmol. 1975;93:119-22.

21. Char DH, Crawford JB, Howes EL Jr, Weinstein AJ. Resection of intraocular squamous cell carcinoma. $\mathrm{Br} \mathrm{J}$ Ophthalmol. 1992;76:123-5.

22. Wexler SA, Wallow IH. Squamous cell carcinoma of the conjunctiva presenting with intraocular extension. Arch Ophthalmol. 1985;103:1175-7.

23. Shields JA, Shields CL, Gunduz K, Eagle RC Jr. The 1998 Pan American Lecture. Intraocular invasion of conjunctival squamous cell carcinoma in five patients. Ophthalmic Plast Reconstr Surg. 1999;15:153-60.

24. Finger PT, Tran HV, Turbin RE, et al. High-frequency ultrasonographic evaluation of conjunctival intraepithelial neoplasia and squamous cell carcinoma. Arch Ophthalmol. 2003;121:168-72.

25. Char DH, Kundert G, Bove R, Crawford JB. $20 \mathrm{MHz}$ high frequency ultrasound assessment of scleral and intraocular conjunctival squamous cell carcinoma. Br J Ophthalmol. 2002;86:632-5.

26. Thomas BJ, Galor A, Nanji AA, et al. Ultra high-resolution anterior segment optical coherence tomography in the diagnosis and management of ocular surface squamous neoplasia. Ocul Surf. 2014;12:46-58.

27. Singh S, Mittal R, Ghosh A, Tripathy D, Rath S. High-resolution anterior segment optical coherence tomography in intraepithelial versus invasive ocular surface squamous neoplasia. Cornea. 2018;37:1292-8

28. Ong SS, Vora GK, Gupta PK. Anterior segment imaging in ocular surface squamous neoplasia. J Ophthalmol. 2016; 2016:5435092.

29. Stone DU, Char DH, Crawford JB, Margolis TP, Van Gelder RN, Strauss EC. Metaplastic squamous epithelial downgrowth after clear corneal cataract surgery. Am J Ophthalmol. 2006;142:695-7.

30. Kamal S, Kaliki S, Mishra DK, Batra J, Naik MN. Ocular surface squamous neoplasia in 200 Patients: a case-control study of immunosuppression resulting from Human Immunodeficiency Virus versus immunocompetency. Ophthalmology. 2015;122:1688-94.

31. Gupta N, Sachdev R, Tandon R. Ocular surface squamous neoplasia in xeroderma pigmentosum: clinical spectrum and outcome. Graefes Arch Clin Exp Ophthalmol. 2011;249:1217-21.

32. Kaliki S, Freitag SK, Chodosh J. Nodulo-ulcerative ocular surface squamous neoplasia in 6 patients: a rare presentation. Cornea. 2017;36:322-6.

33. Mahmood MA, Al-Rajhi A, Riley F, Karcioglu ZA. Sclerokeratitis: an unusual presentation of squamous cell carcinoma of the conjunctiva. Ophthalmology. 2001;108:553-8.

34. Lindenmuth KA, Sugar A, Kincaid MC, et al. Invasive squamous cell carcinoma of the conjunctiva presenting as necrotizing scleritis with scleral perforation and uveal prolapse. Surv Ophthalmol. 1988;33:50-4.

35. Mauriello JA Jr, Abdelsalam A, McLean IW. Adenoid squamous carcinoma of the conjunctiva: a clinicopathologic study of 14 cases. Br J Ophthalmol. 1997;81:1001-5.

36. Robinson JW, Brownstein S, Jordan DR, et al. Conjunctival mucoepidermoid carcinoma in a patient with ocular cicatricial pemphigoid and a review of the literature. Surv Ophthalmol. 2006;51:513-9.

37. Huntington AC, Langloss JM, Hidayat AA. Spindle cell carcinoma of the conjunctiva. An immunohistochemical and ultrastructural study of six cases. Ophthalmology. 1990;97:711-7. 
38. Cohen BH, Green WR, Iliff NT, et al. Spindle cell carcinoma of the conjunctiva. Arch Ophthalmol. 1980;98:1809-13.

39. Arepalli S, Kaliki S, Shields CL, et al. Plaque radiotherapy in the management of scleral-invasive conjunctival squamous cell carcinoma: an analysis of 15 eyes. JAMA Ophthalmol. 2014;132:691-6.

40. Char DH, Crawford JB, Howes EL Jr, et al. Resection of intraocular squamous cell carcinoma. Br J Ophthalmol. 1992;76:123-5. 